\title{
Research on the Knowledge Management Guidance and Enterprise Performance
}

\author{
Llyan \\ Humanity and Management College of Southwest medical university, Luzhou 646000, China
}

\section{Keywords: Knowledge Management Guidance, Enterprise Performance, Research}

\begin{abstract}
Enterprise Big Data era of increasingly competitive and gradually become incandescent, smoke dust on business competition, the core competitiveness of enterprises is particularly important. And the standardization of enterprise management and human resources are the two necessary conditions to build their core competitiveness. Today's business management activities of management by objectives approach is the fundamental goal of full participation, is the business enterprise performance management, and therefore, performance management, business management activities to become the most critical component.
\end{abstract}

\section{Introduction}

The pattern of global integration of economic life not only to speed up the human process of internationalization, but also to speed up the arrival of the era of knowledge economy, the exchange between the peoples of the world more open. Will compete in the field of today's enterprises is mainly reflected in the following areas: personnel, information, capital, knowledge, when companies realize that traditional philosophy has not met the needs of the development of enterprises, companies need innovative management model to promote enterprise development, excellent human resource management and knowledge management guide is to promote enterprise development steady stream of power.

Innovation is the source of economic growth, but also to create the critical core business competitiveness. Management scholars generally believe that companies should use innovation process theory and method of knowledge management to manage. In a typical knowledge management theory, the description of the behavior of the enterprise is under various constraints faced by the enterprise place, in addition to the traditional constraints of price parameters and other aspects of the production function, but also changes in the market and information-rich sexual restraint, restraint and other information technology infrastructure and means. In this prospect, analyze what kind of business management practices, to promote the exchange of knowledge, sharing and application, in order to reduce costs of production and services, or to improve the productivity of capital and maximize profits. However, due to the complexity of the innovation process is different from the dynamic characteristics of the production process and various associated uncertainties, this was to cost or production-oriented knowledge management, enterprise innovation, in theory, cannot be resolved in the process of some essential problems, to management practices in the innovation process, often also appears skills needed.

With the increase in enterprise innovation activities to promote knowledge management, knowledge management has become increasingly oriented decisions innovative performance and management effectiveness of key factors; how to establish knowledge management guide line with corporate innovation inherent law and the fundamental requirements of enterprise innovation management important topics and knowledge management faced.

\section{Related Research on Knowledge Management}

Knowledge management is within the enterprise to establish a humanistic and technical knowledge of both systems, information and knowledge through the integration and configuration, and constantly update their knowledge to achieve optimal configuration, enterprise knowledge management can help companies in the orange sly changing mall on making the right decisions, to 
respond to market changes of requirements.

Although companies at different stages of the innovation process should be taken different knowledge management guide, and the guide as an innovative management indispensable necessary link, can improve the innovation performance of different companies at different times, at different levels and in different degrees. But in fact, we rarely see the cause technical competence appropriate speed improvement, lower unit costs and improve capital productivity coordinated development, mainly due to changes in the probability of innovation while achieving these three areas is very small. Is often the case, businesses can only find one of these three features make the change and innovation, two basic features in the innovation and development of subsequent phases, as is improving the basic result of innovation and change. Therefore, it is determined as the central part of the knowledge management guide for a business of any innovation process has become necessary.

The performance-oriented technology helps companies start from the source of the entire innovation process knowledge management. It is not only able to increase their profitability, but also improve endogenous growth, has become a source of core competitiveness and sustainable competitive advantage, thereby preventing new competitors and reduces the degree of industrial concentration and competitiveness. At the same time, the cost-oriented prices seen steady downward trend In contrast, technology-oriented, the price fluctuations around the equilibrium value is a typical form of development, almost no price drop (long term) and a high price difference. Many simulations have confirmed this finding. In addition, performance-oriented technology is cost-oriented enterprises and capital productivity-oriented premise and basis of the innovation performance of the other two produce a driving effect.

Products and lower production costs per unit of service resulting from cost-oriented, although having a profitable, but is usually accompanied by a decline in the competitiveness of technology, will reduce endogenous growth. If the enterprise knowledge management focused on reducing cost, technical performance remains almost fixed and the relatively backward, endogenous growth and core competitiveness of enterprises will be gradually weakened, difficult to form a lasting competitive advantage. The cost reduction and easy to lead new competitors to enter, form a relatively high degree of industrial concentration and the intensity of competition, which causes easy to get rid of the competitive market. In addition, the decline in price stability but also results in a relatively small price difference are not conducive to the pursuit of profit maximization.

The rate of capitalist-oriented category is neutral between the two guides. In a production rate of capital-oriented knowledge management, profitability may be significant in scale to achieve, but the degree of innovation began to become a spent force, technological competitiveness weakened further, not conducive to long-term competitive advantage and drive out competitors. Therefore, enterprises must return as soon as possible on a technology-oriented, seeking new technological breakthrough, a new round of innovation, will it be possible to maintain long-term innovation performance.

\section{The Business Performance}

Performance in the Oxford dictionary is interpreted as "execution, performance, performance, performance." For the performance point of view together there are three: (1) as a result of performance appraisal basis. (2) acts as a basis for performance evaluation. (3) behavior and results integrated together as the basis for performance evaluation. Foreign scholars Bemadine et al point of view, for "performance and achievement is the result of the work, because these achievements and results and strategic objectives, customer satisfaction, return on capital investment are closely related"; Kane believes that performance "work results and work purposes relative existence." Bemadine and Kane agreed performance is based on the results, as the goal. Murphy is defined as the performance, "performance is the result consistent with the objectives of workplace behavior"; Campben said that "the performance and results are different, it is not the system of other factors, is a behaviors "; Murphy and Campbell also believes that the performance 
of action-oriented. Bminbrach said that the behavior and performance is a comprehensive reflection of the results.

The use of knowledge management is analyzed and performance is the effective output organization or entity to achieve its desired goals and outcomes in various sectors, in particular by the performance of individual performance and organizational aspects of the two components. The presence of organizational performance and individual performance is a certain relationship: individual performance is a prerequisite for the formation of organizational performance, but the realization of individual performance, organizational performance will not necessarily be able to complete. However, if the first organizational performance unbundled, one by one and give each department, each person, then, then when complete individual performance, organizational performance can be achieved. Enterprise is an enterprise performance management during certain operating efficiency and operator performance. The level of operating efficiency of enterprises mainly in terms of profitability, asset management levels, solvency and subsequent development capabilities. The main results of the operator by the operator during the operation and management of enterprises in the outcome of the business, growth, development and made contributions made to reflect. Enterprise performance as a multidimensional variable is the common measure through both financial performance and non-financial performance.

\section{The Nature of the Business Performance}

Excellent or poor business performance affected by a number of internal and external factors, and not just a factor determined by factors that affect performance include: the quality of staff, organizational environment, social environment, natural environment and other aspects. Therefore, the research firm performance, taking fully into account all factors, many visits were analyzed, in order to effectively achieve business performance objectives, managers expect to complete the enterprise.

Performance appraisal of enterprises need to be analyzed and consolidated from multiple dimensions, multiple angles. When we assess the performance of the enterprise, we as well as needto inspect business performance, also taking into account other factors that affect the index of business management. Under normal circumstances, the time to evaluate the performance of enterprises benefit from a financial evaluation, asset management evaluation index, solvency evaluation, development capability evaluation index, evaluation of technological innovation, business process evaluation, knowledge management evaluation, external stakeholders number of indicators were analyzed by evaluation visits. Depending on the purpose of the evaluation, the choice of different dimensions and different evaluation index system which weights vary. This requires us in the design of performance evaluation index system To design a multi-evaluation index system based on the composition of many of the strategy, development priorities, corporate culture and industry characteristics, etc.

Business performance is not fixed and it will be with the conversion time, the production process and change. Business performance may deteriorate by the presence of good, good from bad, good sustained, continued poor several forms. Since corporate performance have such characteristics, we need to continue in the conversion process of performance management, change our thinking, dynamic analysis, with the development of thought to control the situation on Corporate Performance.

\section{Impact of Knowledge Management Guide on Business Performance}

In the era of knowledge economy, knowledge has become an important resource for companies to gain competitive advantage, strengthen knowledge management has become an important means for enterprises to enhance their ability to innovate, to gain competitive advantage. Catherine L.Wang made knowledge management concepts to guide empirical proof of having a positive relationship between knowledge management and enterprise-oriented performance. Enterprises optimize the knowledge structure can facilitate knowledge sharing within the enterprise, conversion, creation and 
application of knowledge to optimize resources and orderly process of knowledge management will effectively enhance corporate performance .Sabeherwal Knowledge Spiral Model Analysis Based on the Knowledge Management and Enterprise contextual performance, studies have shown that social knowledge will positively affect organizational effectiveness, the basic mechanism is self-efficacy on team performance, team performance affect business performance. Davidson and Voss that knowledge management is the business strategy itself, at the appropriate time to transfer appropriate knowledge to those who need it most to help them create and apply knowledge, and ultimately improve business performance. Lee believe that knowledge management is a complex process, would be enhanced by the knowledge management process innovation capability of enterprises, and ultimately enhance the business performance .Sabherwal. R Sabherwal. S also confirmed knowledge management can contribute to corporate performance process Xie Hongming Taiwan-based high-tech enterprise survey found that effective use of knowledge management with new product development performance and positively correlated Lizheng Feng Ye Jinfu based aviation enterprise knowledge management activities with the investigation confirmed that the performance of aeronautical development of new products have a significant relationship. Scholars have said the level of support for enterprise knowledge management enterprise performance relationship.

Knowledge management is different from the enterprise information management as the core of knowledge through knowledge sharing to achieve enterprise management activities. The ultimate goal of enterprise knowledge management is a high performance body corporate. Enterprises through modern information technology, development expertise resources, improve the ability of employees to use knowledge resources. Enterprise knowledge management can effectively enhance creativity, provide fertile ground for the growth of business creativity, creativity as the core competitiveness of enterprises an important manifestation of the form and it is possible to promote the process of modernization of enterprises, and continuously improve the economic efficiency of enterprises.

\section{Conclusion}

As knowledge management guide has a decisive influence on the business performance and innovation process at different stages and require different knowledge management guide which adapts, therefore, companies must optimize the selection process of innovation in knowledge management guide. Due to technical performance-oriented enterprises is the central link in the innovation process, both to significantly enhance their innovation activities profitability, but also significantly improve the endogenous growth and core competitiveness of enterprises, so enterprises innovation process must be based on knowledge management as the basic technology-oriented innovation activities, promote cost-oriented and capital productivity-driven innovation, enterprise innovation activities in the spiraling cycle of virtuous cycle.

\section{References}

[1] HeHuitao: Foreign Economics and Management, Vol. 6 (2014) No 53, p.25-26

[2] Li Guangbin: Economic Science, Vol. 12 (2015) No 27, p.74-76

[3] Qin Guo: Engineering Management, Vol. 1 (2012) No 33, p.11-14

[4] Jieming Liu: Guangxi Normal University, Vol. 3 (2011) No33, p.121-124

[5] Qin Guo: Engineering Management, Vol. 1 (2012) No 33, p.11-14 